This PDF is a selection from a published volume from the National Bureau of Economic Research

Volume Title: Innovation Policy and the Economy, Volume 3

Volume Author/Editor: Adam B. Jaffe, Josh Lerner and Scott Stern, editors

Volume Publisher: MIT Press

Volume ISBN: 0-262-10100-9

Volume URL: http://www.nber.org/books/jaff03-1

Conference Date: April 16, 2002

Publication Date: January 2003

Title: Intellectual Property and the Availability of Pharmaceuticals in Poor Countries

Author: Jean O. Lanjouw

URL: http://www.nber.org/chapters/c10794 


\title{
Intellectual Property and the Availability of Pharmaceuticals in Poor Countries
}

\author{
Jean O. Lanjouw, Brookings Institution, Center for Global Development, \\ and University of California at Berkeley
}

\section{Executive Summary}

There continues to be widespread criticism of the extension of patent rights on pharmaceuticals in the developing world as required by World Trade Organization membership. This chapter examines arguments in favor and against this strengthening of worldwide patent protection. It emphasizes that these new pharmaceutical patents promise benefits and costs that differ according to the characteristics of diseases. Some diseases primarily affect poor countries. For these diseases, patents will not be sufficient to attract substantial private investment, because purchasing power is low. However, globally available and well-defined patent rights could increase the benefits derived from greater public financing of research on pharmaceutical products for the developing world. For major global diseases the justification for extending patents in poorer countries is less clear. Thus the optimal global framework for pharmaceutical patents might require differentiating the protection given to products in accordance with their extremely different global markets. The chapter considers standard intellectual property and regulatory mechanisms that could be used to differentiate protection. All have serious drawbacks. It then describes a new mechanism that would make differentiating protection a more feasible policy option.

\section{Introduction}

Recent agreements involving intellectual property will result in a significant extension in the global patent rights available to pharmaceutical firms. At the close of the Uruguay round of the General Agreement on Tariffs and Trade (GATT) in 1994, members agreed to a common set of international rules against a background of long-running bilateral pressure on selected developing countries to strengthen their patent laws. ${ }^{1}$ Many developing countries have excluded pharmaceutical innovations from patent protection, offering only very brief protection for 
new manufacturing processes. Now all members of the World Trade Organization (WTO) are expected to implement new laws that look very much like those in the U.S. and Europe, if they have not done so already. ${ }^{2}$

The implications of this expansion of rights, and the question of whether the global framework for intellectual property is now appropriate, have been sources of continuing, often intense disagreement. The initial debate in the context of the GATT negotiations revolved around whether intellectual property was even a legitimate subject for a trade treaty. Those in favor of its inclusion finally prevailed in the form of the TRIPS component of the Agreement Establishing the World Trade Organization (Trade-Related aspects of Intellectual Property, Annex $1 \mathrm{C}$ ). The issue was reawakened as the public became more aware of the rapid spread of HIV/AIDS, together with the discovery of expensive patented drugs to treat the disease. Today there continues to be widespread criticism of the international framework for patent rights laid down in TRIPS as it applies to pharmaceuticals. Views in the developing world range from uneasy acceptance to outright rejection, and the potential effect of the new regime on health in these countries has also raised active concern elsewhere. ${ }^{3}$

It is important that the divergent interests involved in this debate arrive at a more broadly acceptable system. The simple fact that the TRIPS-based global architecture has generated such resistance is damaging in a variety of ways. Pressure groups are driving changes to the system of patent rights and using targeted campaigns to lower particular drug prices. Regardless of the merits of individual results, this is a process of change that is both costly and extremely unpredictable in its effect. The uncertainty this creates about future markets and pricing opportunities is itself a strong deterrent to private sector involvement in drug research for the developing world. Dissatisfaction with the patent system in the realm of health may also spill over into a distrust of the intellectual property system more generally. This possibility should concern anyone who considers patents to be an important stimulus to innovative effort. Finally, regardless of what treaties are signed and laws passed in the poorer countries, reliable and consistent patent systems there can only be established with local support. ${ }^{4}$ Effective enforcement cannot be imposed from the outside.

Unfortunately, the debate over drug patents in poor countries has become very polarized, which makes finding an acceptable system dif- 
ficult. Positions tend towards two endpoints. At one end are those who support the current move toward a system where all countries have the same form of intellectual property laws, and where the protection afforded pharmaceutical inventors is at the level now available in the developed countries. At the other end are those who view the higher prices sustained by pharmaceutical patents as too burdensome in poor countries and advocate either no patents for drugs in the developing world or expansive compulsory licensing provisions.

Any policy discussion in this area should start from the recognition that granting inventors intellectual property rights inevitably entails a trade-off. Not, as it is sometimes cast, between corporate profits and public health. Rather, between two equally important public health goals: widespread access to existing drugs and the maintenance of incentives to create new ones. The higher prices sustained by patents finance the search for new innovations, but higher prices also mean that fewer consumers can purchase goods incorporating those innovations. ${ }^{5}$ Whether an extension of patent rights is desirable depends importantly upon the extent to which the prospect of greater profits leads firms to increase research investment, and the degree to which each additional dollar of investment results in beneficial innovation. These both decline at higher levels of $R \& D$ investment. ${ }^{6}$ As a result, one can expect more benefit from increasing protection where incentives are initially low.

In light of this, one of the strongest arguments of the pharmaceutical industry when advocating the adoption of strong patent systems in the developing world has been the claim that the availability of patent rights there would encourage more private investment in products tailored to the specific needs of poor countries. There is a substantial list of "neglected diseases" that are prevalent in poor countries and almost absent in rich countries. These have few, if any, effective treatments and have seen almost no investment by the private sector and little by the public sector. It is hard to disagree that pharmaceutical policy targeting such diseases should focus primarily on attracting more research-products must exist before they can be made available. ${ }^{7}$

Two questions are raised by industry's argument, however. First, is it important that private firms be involved in the search for new products? And, if the answer is yes, should the availability of patent protection in the developing world be part of the incentive established to encourage their involvement? 
Industry's argument highlights a more general point—that there are two extremely different types of drug markets. Their argument focuses on diseases specific to developing countries, and for those it has most merit. However, there are many global diseases that are widespread in poor countries and also in rich countries. Because drugs to prevent and treat global diseases already enjoy large western markets, the tradeoffs associated with the extension of patent rights to poor countries look very different for such drugs. While it may be important to ensure inventors protection in poor countries to increase malaria research, it is less obvious that it is good policy to encourage cancer research in this way. Drug markets differ, and as a result the optimal geographic extent of protection for pharmaceutical innovations also differs across diseases.

This chapter considers some of the arguments for the extension of pharmaceutical product patents in poor countries. The following section discusses the basic justification for granting patent rights and for placing limits on them. Section III considers products for diseases primarily affecting the developing world, and section IV considers products for global diseases. The focus for each type of disease is on the potential effect of extended patent rights on the rate of drug innovation and the access of the poor to existing pharmaceuticals. (Patents may play other roles, such as facilitating contracting between firms. See Lanjouw 1998.) Section IV also considers the importance of patents in the developing world as a tool to preserve incentives in developed country markets.

Economists and policymakers have been reluctant to differentiate protection across types of innovation despite the fact that there is often a strong theoretical basis for doing so. In keeping with this, the TRIPS Agreement explicitly requires nondiscrimination. There are good reasons for this reluctance. The information needed to decide how best to differentiate is limited, and any differentiation must be on features both easily identified and hard to change or resources will be wasted as patentees try to fit into the better class. ${ }^{8}$ Section $\mathrm{V}$ assesses the potential for using standard intellectual property and regulatory policies to offer different global protection to drug innovations for the two types of diseases. All are problematic. Section VI outlines a new mechanism to differentiate protection that has some important advantages. With this mechanism, protection could be allowed to continue increasing worldwide in situations where stronger incentives to invest in research could be important-but delay an increase in protection in those where 
a marginal increase in profits would be unlikely to generate new innovation. In contrast to any of the standard policy approaches, use of the mechanism would create a global patent framework where coverage would both adapt to the evolution of markets for different diseases and broaden automatically to cover all pharmaceutical inventions as a country developed. Section VII concludes.

\section{The Underlying Justification for the Grant of Patent Rights}

To discover and develop a new product typically costs far more than to copy it. Thus, without some protection, entry by imitators can quickly erode the profit available to the actual inventor. Knowing this, potential investors will be discouraged from committing sizable sums to research. When inventors capture only a part of the benefit to society of their innovations, private returns do not reflect social returns and the result is too little investment in R\&D. Firms are able to protect inventions and limit competition in a variety of ways: by keeping their innovations secret, by taking advantage of lead time, with brand advertising, and so on. However, government-granted patent rights can be an important source of market exclusivity. ${ }^{9}$ This is particularly so for the pharmaceutical industry because drug innovations are relatively straightforward to imitate (Cohen, Nelson, and Strauss, 2000). On the other hand, once a product exists welfare is best served by having it priced close to marginal production cost. Otherwise there are consumers who would be willing to pay the cost of producing the product who do not get it (the deadweight loss). This is the cost side of supporting research through a patent system.

The intellectual property laws in all countries recognize this inherent trade-off in a variety of ways. It is, for example, the basis of statutory term limits in patent law. The longer protection continues, the larger becomes the incentive to invest in research, and on this account one might want infinite-lived patents. However, the longer protection continues, the longer consumers must wait for competitive entry to lower prices. At a certain point, the latter cost is viewed as outweighing the former benefit, so the patent term is limited (for a formal analysis, see Nordhaus 1969 and Scherer, 1972). ${ }^{10}$

Countries also acknowledge this trade-off in their choices to limit protection for certain types of inventions. Historically, most countries have had very restricted protection for pharmaceutical and agriculturerelated innovations. ${ }^{11}$ The reasons are twofold. First, patent rights in 
Table 4.1

Development level on adoption of pharmaceutical product patents

\begin{tabular}{llc}
\hline Country & $\begin{array}{l}\text { Year of } \\
\text { adoption }\end{array}$ & $\begin{array}{l}\text { GDP per capita } \\
(1995 \text { U.S. } \$)\end{array}$ \\
\hline Panel A: OECD adopters & & \\
Japan & 1976 & 24,043 \\
Switzerland & 1977 & 36,965 \\
Italy & 1978 & 13,465 \\
Holland & 1978 & 20,881 \\
Sweden & 1978 & 21,896 \\
Canada & 1983 & 16,296 \\
Denmark & 1983 & 28,010 \\
Austria & 1987 & 25,099 \\
Spain & 1992 & 14,430 \\
Portugal & 1992 & 10,469 \\
Greece & 1992 & 10,897 \\
Norway & 1992 & 30,389 \\
Panel B: Recent adopters & & \\
China & $1992 / 3$ & $424^{\mathrm{a}}$ \\
Brazil & 1996 & 4,482 \\
Argentina & 2000 & 8,100 \\
Uruguay & 2001 & 6,208 \\
Guatemala & Future & 1,545 \\
Egypt & Future & 1,191 \\
Pakistan & Future & 508 \\
India & Future & 450 \\
Malawi & Future & 156 \\
\hline
\end{tabular}

${ }^{a}$ GDP is for 1992. For countries adopting after 1999 the GDP per capita figure is for 1999. Sources: Years of adoption, Santoro (1995) and Richard Wilder (personal communication); GDP statistics, The World Bank (2001) World Development Indicators CDROM.

other countries were available to stimulate research investment. Since they could free-ride on the products brought about by others' patents, the benefit of increasing protection in their own markets was relatively small. Second, because food and health are basic needs, higher prices due to patents in these areas are more acutely felt, particularly at lower levels of development. This also makes food and drug prices politically sensitive. Over time, pharmaceutical protection was adopted throughout the developed world, but only slowly. The top panel of table 4.1 presents adoption dates for many OECD countries and indicates their GDP per capita at the time pharmaceutical protection was first offered. Spain and Norway, for example, introduced patent protection for pharmaceutical products only in 1992, when their GDP per capita had 
reached $\$ 14,430$ and $\$ 30,3871995$ U.S. dollars, respectively. The second panel of the table gives the current GDP per capita of selected developing countries that have recently undertaken to introduce pharmaceutical product patents.

\section{Developing-Country-Specific Products}

The developing countries now extending protection to pharmaceutical products are at a considerably lower level of income than those adopting earlier. This makes the policy change particularly costly for them, since price increases matter more in poor countries. In addition to having little income, poor consumers are rarely insured and must pay for pharmaceuticals directly out of pocket when subsidized public supplies are not available. ${ }^{12}$ However, there is a rationale for the developing countries to extend protection even while relatively poor, because they do not face the same trade-offs. ${ }^{13}$ Unlike the earlier adopters, they have pharmaceutical needs that are not shared by countries already offering patent protection. This is for two reasons. First, they have disease patterns that are quite distinct. For twenty diseases, at least $99 \%$ of the global disease burden is concentrated in low- and middle-income countries. Together these diseases are estimated to have caused the loss of almost 200 million disability-adjusted life years (DALYs) in 1998, and over 5 million lives, a large share of them children. ${ }^{14}$ The A strain of the HIV virus is also particularly widespread in poor countries but not in the developed world. HIV/AIDS is estimated to have killed 2.3 million people in Africa last year (UNAIDS / WHO 2001). For these diseases there simply is no free ride.

Second, even for a global disease like cancer, the characteristics of some poor countries may make the many products designed for western markets unsuitable. For example, tropical countries with weak infrastructure need pharmaceutical products that can withstand breaks in a distribution cold chain and survive a long shelf life. Drug discoveries that are very cost-effective, but less effective overall, may not be acceptable to rich consumers and hence not developed by pharmaceutical firms even though they would be of great benefit to poor consumers. The choice between vaccines and drug therapies is yet another example. An HIV / AIDS vaccine would be far easier to deliver in a poor country than drug therapy cocktails, but efforts to develop a vaccine have been minimal in comparison with the investment in 
treatments. Thus, even for a global disease, for which there are many pharmaceutical products, there may be few tailored to the specific needs of the developing world.

\section{Little Investment and Innovation}

Because serving poor consumers in the developing world is not attractive relative to their other commercial opportunities, commercial pharmaceutical firms have directed only a minute fraction of their research expenditure toward creating products for developing-country markets. ${ }^{15}$ Médecins Sans Frontières (2001) report on a survey of major drug firms conducted with the Harvard School of Public Health. Their eleven respondents (of 20 canvassed) had a combined research expenditure of nearly $\$ 117$ billion. Over the past year, three had invested in drugs for leishmaniasis or Chagas disease, just two in drugs for malaria, and none in drugs for African trypanosomiasis. Public sector investment in pharmaceutical research has also been extremely low in relation to the tremendous welfare cost of diseases primarily affecting poor countries and the paucity of drugs to prevent and treat them. Médecins Sans Frontières (2001) provide estimates by experts that noncommercial research expenditure on drugs for TB, malaria, African trypanosomiasis, and leishmaniasis combined was less than $\$ 100$ million in 2000 (which they compare with the $\$ 3.1$ billion in public expenditure devoted to cancer research in the U.S. alone). Taking public and private expenditures together, the World Health Organization (1996) estimated that, in 1992, $\$ 2.4$ billion, or just $4.3 \%$ of global health-related R\&D expenditure, was related to health problems of low- and middleincome countries. ${ }^{16}$ Only $0.2 \%$ was spent on pneumonia, diarrheal disease, and $\mathrm{TB}$, diseases that together accounted for $18 \%$ of the total global disease burden.

Although there have been some successful public sector programs, it is evident in the results that these limited investments have largely failed to generate either basic innovation or products for pressing health needs of the poor. Lanjouw and Cockburn (2001), for example, examine basic research activity through citations in bibliometric databases covering approximately 3900 worldwide biomedical journals. References to the set of tropical diseases (those with $99 \%$ of their burden in poorer countries) occurred in less than $1 \frac{11}{2} \%$ of all citations in 1998. Considering patenting activity, which is more closely linked to products, only about $1 / 2 \%$ of all pharmaceutical patents in 1996 
related to these diseases. ${ }^{17}$ Pecoul et al. (1999) report that only eight of 1233 drugs licensed anywhere in the world from 1975 to 1997, or less than $1 \%$, were developed specifically for tropical diseases in humans (five more were for designed for veterinary uses). Médecins Sans Frontières (2001) note that recent surveys of drugs in development by PhRMA, the U.S. industry association, showed just two drugs related to the most neglected diseases, of 137 medicines in the pipeline for infectious diseases. There is considerable scope for greater effort.

\section{Is Engaging the Private Sector Important?}

Increasing the involvement of the private sector could enlarge the pool of resources to address specific health needs of poor countries and also raise the productivity of public investment. The first is important because exclusive reliance on the public sector will almost certainly fail to deliver substantial new investment in pharmaceutical research. ${ }^{18}$ If new funding does get allocated to health research, it may only be at the expense of other development needs with their own valid claims to resources. Philanthropic donations, such as the $\$ 80$ million donated by the Bill and Melinda Gates Foundation over five years for pharmaceutical research related to malaria, TB, leishmaniasis, and African trypanosomiasis, are a very significant contribution to the resources available (Médecins Sans Frontières 2001). However, pharmaceutical $R \& D$ in the private sector reached $\$ 25.7$ billion in 2000 and continues to grow. ${ }^{19}$ Small market opportunities that shifted even a tiny fraction of that investment in the direction of products for poor countries could be an important boost to public and philanthropic efforts.

Irrespective of the ultimate source of research funding, new products may be obtained more efficiently, that is, at lower cost, by engaging the private sector. Commercial firms have financial goals, which keeps their research programs responsive to the demands of consumers. This is sometimes portrayed as a negative attribute-when demand is high for solutions to dog obesity (though the blame, if any, should rest with dog owners). But their commercial motivation has the important benefit that research priorities can be directed with market signals. By contrast, ensuring that public sector researchers pursue program goals effectively requires monitoring and this can be weak. (See Kremer 2001 for a discussion of the problems encountered with public sector research on vaccines.) 
Pharmaceutical firms also have a comparative advantage in some later-stage activities. They have the experience and the infrastructure to take products through the multiple phases of clinical trials required for approval by health authorities throughout the world. Firms have in place marketing networks that can be used to move new products out to doctors and patients. It is possible, and may be desirable, for the public sector to take a few selected products from basic research through commercialization (a vaccine, for example, where the buyers are largely limited to governments). However, building up the public sector capacity that would be necessary to take a broad range of new products successfully through to commercialization would be a costly alternative to harnessing the skills that are already available in the private sector.

\section{What is the Role of Patents?}

It is clear that the extension of patent protection in the developing world will not, by itself, cause private investment to pour into products specific to their markets. Their consumers have too little purchasing power. WHO estimates that 17 countries spent no more than $\$ 10$ U.S. per capita in 1998 on all health expenditures, not just pharmaceuticals. Over a third of all countries spent less than $\$ 50$. By contrast, twelve countries are estimated to have spent over $\$ 2000$ per capita on health (WHO 2001). ${ }^{20}$ In fact, the industry points out that it often does not patent in the poorest countries even when the opportunity is available, because there is so little prospect of profit. This is supported by a report on the patent status of 15 antiretroviral drugs in 53 African countries in mid-2001 (Attaran and Gillespie-White, 2001). In the report a drug is considered patented if it is protected by either a (granted) process or product patent, or by exclusive marketing rights (an interim form of protection allowed in the transition period established for poor countries under TRIPs). Outside of South Africa, where 13 of the 15 drugs had been patented, they found that patenting was very limited: the median number of antiretrovirals under protection was just three per country.

While industry uses this fact to stress that patents in the poorest countries are not impeding access to drugs, it also means that pharmaceutical patents there are not stimulating research. More dollars are needed-patents are clearly not sufficient. ${ }^{21}$ In policy discussions, methods to subsidize research with public funds are often character- 
ized as either push or pull mechanisms. Push mechanisms subsidize research inputs up front, while pull mechanisms promise to pay for a specific product with defined characteristics only once it is developed. Kremer (2001) outlines various ways in which a pull mechanism could be structured and provides a detailed discussion of the merits of the two approaches in this context.

Although patents in the poor countries are not sufficient to elicit sizable investment in products addressing their specific needs, they may still be desirable as part of a package of policies. A role for patents is most obvious in conjunction with pull mechanisms designed to replicate a market. These use international development funds to bolster weak consumer purchasing power. As in a normal market, patent protection is important to ensure that original inventors can be identified and rewarded and to prevent them from being undercut in some markets by cheaper imitations.

The role of pharmaceutical patents is less obvious with push mechanisms, where public money finances research and development costs up front. It is argued that patents would effectively make the public pay twice, with firms obtaining monopoly profits and denying to the public use of the inventions that it has financed. However, there are advantages. If public funding is only partial, perhaps limited to basic research, it may be important to allow firms to garner whatever profits are available in the market to cover development and marketing costs. Further, uncertainty is costly. Investors require a higher return when there is more risk. For this reason, attracting a given level of investment from the private sector becomes more costly when firms are unsure of the rights they will hold at the end of the research process. The availability of patent rights, and clear rules about how they will be interpreted, can reduce uncertainty by defining ownership rights in a way that is familiar to firms. The fact that most owners of antiretrovirals chose to seek protection in (much richer) South Africa clearly shows that firms do want to establish their rights as soon as a potential market appears.

Deciding the appropriate bounds on intellectual property rights when research is publicly funded is an issue that has been debated in the U.S. for over a century, the topic of over forty congressional hearings and reports and four special commissions between 1940 and 1975 (Jaffe and Lerner 2001). Since the early 1980s, the U.S. government has taken the position that it is important to give private researchers relatively generous rights over inventions coming out of publicly funded 
research programs in order to obtain the most benefit from the public investment. With the Bayh-Dole Patent and Trademark Amendments Act of 1980, for example, the federal government allowed small businesses and nonprofit organizations to retain ownership of patents on government-sponsored research results and to license them on an exclusive basis to firms for development. Shortly thereafter this right was extended to all government contractors, including large firms. ${ }^{22}$

It is important to recognize that the mere fact that patent rights are available does not imply private control over innovation. Patents can also be taken out by the government, by universities, and by international and other organizations. If new products for poor countries' health needs are developed within the public sector, the public sector may hold the patents. Nor does the establishment of clear property rights mean that they must be unconstrained. Cooperative Research and Development Agreements (CRADAs) in the U.S., for example, are formal contracts between government-operated laboratories and private firms that allow cost-sharing industrial partners to own or exclusively license any patented inventions that result from collaborative research. ${ }^{23}$ This right may be limited, however, if the partner does not meet performance benchmarks. A more targeted program is the International AIDS Vaccine Initiative (IAVI), which seeks to coordinate research efforts between the public sector, academia, and industry. Industry partners hold the patent rights for the exclusive marketing of any vaccines developed, subject to the condition that patented vaccines will be sold to the governments of developing countries at "affordable prices." Failing that, IAVI obtains the right to license the patent to an alternative producer on a nonexclusive basis for this (limited) purpose (United Nations Development Programme, 2001). Under Bayh-Dole, the U.S. Federal Government retains march-in rights to revoke ownership and licensing privileges if an invention is not developed and made available on reasonable terms to the public.

Of course, any limitations on patent rights need to be well defined in advance or the benefits of clarity are lost. In hearings before Congress concerning Bahy-Dole, industry objected to vagueness in the terms, insisting that government only be able to use its march-in rights ". . . after a full and complete hearing before an impartial arbiter based on clear and convincing evidence. ... Likewise, the circumstances under which the rights can be exercised must be precisely defined and avoid such vague terms as 'welfare' and the like." (quoted in Arno and Davis 2001). Limitations also must be enforced. Arno and Davis (2001) point 
to government's failure to set up an administrative process that would allow it to exercise its march-in rights effectively. (See also their op-ed in the Washington Post, March 27, 2002.)

The Bayh-Dole Act and related legislation appear to have had the desired effect. Mowery and Ziedonis (2001) report that the number of universities with technology licensing and transfer offices increased from 25 in 1980 to 200 in 1990, and licensing royalties almost doubled between 1991 and 1994. Thus, the incentive given to university administrators to find technology buyers seems to have successfully increased the commercial use of government-funded academic research output. Similarly, Jaffe and Lerner (2001) find a strong increase in patenting by U.S. national laboratories after the passage of the StevensonWydler Technology Innovation Act of 1980, legislation intended to encourage greater technology transfer from the laboratories. ${ }^{24}$

\section{Patents Also Encourage "Low Profile" Innovations}

A publicly funded research program, whether push or pull, needs to have clear and limited objectives. Public and philanthropic efforts naturally focus on major pharmaceutical needs. As discussed, patent rights can contribute to the success of these targeted projects. A further advantage to having patents available in the developing world is easily overlooked. Without direction or control, patents engage numerous independent entities in the search to find new or adapted products for any purpose that might offer some return. ${ }^{25}$ Most of these products would not, individually, be significant enough to attract public attention and resources. However, by their sheer number they could, taken together, be of considerable value to poor consumers. Just to give some perspective, the U.S. Patent and Trademark Office (PTO) granted over 10,000 patents related to pharmaceuticals in 1998 alone; and in 2000 the U.S. Food and Drug Administration (FDA) approved about 750 different drug and blood-related products. It would be completely infeasible to set up research programs to target the range of products that might find a small but profitable market in the developing world.

In sum, the primary issue for pharmaceutical policy related to developing-country-specific health needs is to increase the level of investment in the discovery and development of new products. Market incentives have been largely missing, both because people in the developing world are poor and because intellectual property rights for drugs there have been very circumscribed. Stronger patent rights alone may 
encourage firms to make small investments to find new products or adapt existing pharmaceuticals to poor-country needs. These new investments will not be substantial, of course, unless there is also an increase in funding. The availability of (possibly limited) clear and reliable patent rights in poor countries could complement policies to stimulate research with public funding. Pull mechanisms that would replicate a market, for example, are assumed to utilize an existing patent system. These have been receiving considerable attention recently. Similarly, patent rights may contribute to the productivity of direct public research funding (push) by lowering the risk associated with investing in this area and encouraging industry involvement. Thus, for developing-country-specific needs, where the creation of stronger incentives to discover and develop new pharmaceuticals is of paramount importance, there is a rationale for poor countries to have patents in place.

\section{Global Diseases}

Consider now global diseases. Although this class of diseases has received less attention in development debates over intellectual property, they are also an important and growing source of disability and mortality among the poor. Cancer, heart disease, and diabetes, for example, already account for $16 \%$ of all DALYs lost in low- and middle-income countries, a group having a weighted average GDP per capita of $\$ 1250$. This is four times the share lost to malaria (WHO 1999). An Economist report on recent research into the rapid rise in obesity in poor countries emphasizes that it will have a dramatic effect on disease patterns and the incidence of diet-related noncommunicable diseases. They report; for example, that the number of new cases of adult-onset diabetes in China and India already exceeds the number of new cases in the rest of the world combined (The Economist, February 23, 2002) ${ }^{26}$

While global diseases impose major suffering on the poor, their low purchasing power means that consumers in poor countries represent a very small part of the total market for drugs for global diseases. For example, about $46 \%$ of the world's population is found in countries representing less than $2 \%$ of total expenditure on drugs for cardiovascular disease. As another example, countries with GDP per capita less than $\$ 2500$ together contributed less than $1 / 2 \%$ to global spending on antiretroviral drugs in 1999 [IMS and World Bank (1999) data, own calculation; see Lanjouw (2002a) for further evidence]. Thus, for the same reason 
that patents in poor countries will not, by themselves, encourage much private research on developing-country-specific diseases, they create almost no additional stimulus to research on global diseases.

It was argued in the previous section that, in spite of the weak incentives generated by patents in poor countries, pharmaceutical patents might nevertheless be valuable in those areas of research for which the developing world is the primary market. One might also argue that there is underinvestment in all areas of pharmaceutical research and that therefore increasing the geographic reach of patent protection would be desirable even for global-disease products with profitable markets in rich countries. But this is less convincing. Once there are pharmaceuticals available to treat a disease, the consumer benefit of additional research begins to fall. It is well documented that diseases with large markets call forth large amounts of duplicative research. A study of 775 new chemical entities (NCEs) introduced into the world during the period 1975-1989, for example, reports that a group of experts rated only 95 as truly innovative (Barral 1990). More recently, the U.S. FDA considered fewer than half of the new molecular entities it approved during 1998-2001 to be significant improvements over already marketed products in the treatment, diagnosis, or prevention of a disease..$^{27}$ If, nevertheless, one wants to use the patent system to marginally increase research on global diseases, there remain a wide variety of options. For example, the statutory term of protection in rich countries could be extended by a month or two. Introducing new patent rights in the poor countries is not clearly the best of those options.

In fact, no one who advocates that pharmaceutical patents be extended in poor countries suggests that it is because there is insufficient investment in cancer research. Two other arguments are proffered in relation to global diseases. The first is that innovating firms will be slow to launch their new products in poor countries without protection there. Patents would speed the arrival of new pharmaceuticals. There is no clear evidence to support this view. The second is that they will help protect rich-country markets that are increasingly at risk from "flowback." This argument has merit, but alternative policies to attain the same end have advantages.

\section{Patents to Speed Product Introductions}

Obtaining marketing approval and educating doctors about a new drug requires a sizable investment. Absent patent protection, entrants 
can free-ride on the introductory marketing efforts of the first firm and make its expenditure on the initial launch unprofitable. This argument in favor of product patents was heard in the leadup to TRIPS, and support for it was drawn from evidence that many drugs are not available in developing countries. However, this may not be due to a lack of patent protection. Other legal features, such as inappropriate regulatory procedures, may limit pharmaceutical introductions in poor countries (Kremer 2002), and price controls may also discourage market entry. To put this evidence in context it is also useful to consider again the study by Barral (1990). Of the 95 NCEs classified as innovative, he found that $31 \%$ were being marketed in no more than five of the seven largest pharmaceutical markets. ${ }^{28}$ In other words, even among new drugs deemed to offer a therapeutic advantage, a significant portion were not introduced by the patentee in developed-country markets protected by product patents.

It is also not necessary that a country rely on the innovating firm to introduce new drugs. In the absence of patent protection, generics manufacturers or firms in developing countries are also able to enter the market. The latter have shown themselves to be adept at rapid imitation and willing to incur the costs of launching new products. Over the past two decades, for example, copies of major patented drugs typically arrived on the Indian market within seven years of their world launch-often much earlier-and the speed of imitation appears to have increased (Lanjouw 1998, Watal 2000). For ten drugs launched in the U.S. after 1985, Watal finds an average time lag to availability in India of just two years. The U.K. multinational Glaxo faced several local competitors from the first day that its subsidiary marketed its proprietary drug ranitadine (Zantac) in India.

Granting protection may speed the arrival of new drugs on the market by making the process of adapting a product, getting marketing approval, and introducing it to consumers profitable. However, giving patentees control over drug introductions may actually slow down diffusion. A multinational with a newly patented drug may delay launches in poor countries because of concerns over global price regulations (see below). For example, Bayer chose not to introduce its patented drug ciprofloxacin in India because it would have had to sell it at what Bayer viewed as, at that time, too low of a price. Instead, ciprofloxacin was introduced three years after its world launch by the Indian firm Ranbaxy. In 1996, more than eight years after its world launch and long after the entrance of a multitude of local producers, 
Bayer also began marketing ciprofloxacin in India (interview with Bayer executive, India, 1997). If patentees hesitate to introduce drugs at low prices in the initial years of global marketing, and with imitators prevented from entering, innovative pharmaceuticals may actually become available in poor countries more slowly than they would have in the absence of protection.

\section{Patents to Prevent Damage to Rich-Country Markets}

The more recent argument suggesting that poor countries should extend their patent laws to include pharmaceutical products even for global diseases does not relate to them directly, nor to profit opportunities in their markets. It is argued that if innovating firms are not allowed control over the global distribution of their products, then they will be unable to protect their primary sales base in the rich countries. This is important. If generic competition in poor countries erodes profits in the rich countries, it could significantly dampen research incentives and slow the creation of new products. On that account, consumers in all parts of the world would be harmed.

There are two ways in which profit erosion might occur. The most important is due to cross-country price comparisons. Consumers in rich countries object to paying higher prices than they see being charged to consumers in other countries and put pressure on companies, through their representatives in government, to lower prices. This has been seen most recently in the furor over lower Canadian prices for patented products and the passage of legislation (subsequently suspended) to allow the reimport of certain drugs into the U.S. ${ }^{29}$ It does not always help that the other countries are poor. A disheartening example is that of the UNICEF vaccine program. Prior to 1982, European and American manufacturers bid to supply UNICEF with vaccines for poor countries at low prices. "In congressional hearings in 1982 concerning federal and state expenditures for the purchase of children's vaccines . . . the U.S. vaccine industry was savaged for allegedly subsidizing vaccines for the poor children of the world by charging high costs to U.S. families and taxpayers" (Institute of Medicine 1997; emphasis mine). Regulatory systems can reinforce political pressures. Drug prices in developed countries are increasingly regulated on the basis of global reference pricing, a system in which the price ceiling allowed for a new drug is linked to the price charged by the patentee elsewhere. ${ }^{30}$ 
Whether comparisons are made by consumers or by government regulators, the problem is most acute when a patent-owning firm itself markets its product in poor countries at lower prices. Competitive pricing by imitating firms reveals some information about marginal production costs that could be used to pressure the innovating firm. However, imitators' products could be presented as having quality or other characteristics justifying a difference in price.

Although the examples above indicate that consumers have been sensitive to price, it is also the case that patentees have launched their patented products in countries that did not offer them protection at very substantially lower prices without attracting attention. Until the anthrax scare in October 2001, the drug recommended to combat the disease, ciprofloxacin, was being sold by the patent owner, Bayer, in the U.S. at a wholesale price of about $\$ 4.60$ for a $500-\mathrm{mg}$ tablet and at a Federal Government price of $\$ 1.83$. Meanwhile, it was being marketed in India by 78 firms, including Bayer, for about 10 cents a tablet (Wall Street Journal, October 19, 2001). Similarly, the antiulcer drug Zantac was being sold by the patentee, Glaxo, at about $\$ 2.80$ for $300 \mathrm{mg}$ in the U.S. at the time of patent expiration in early 1996. At the same time, Glaxo sold the same product in India under the brand name Zintec for less than 6 cents. Another antiulcer medication, Tagamet, was sold by the patent owner at about $\$ 2.25$ for $800 \mathrm{mg}$ in the U.S. at the time of patent expiration and was sold for about 11 cents in India by Cadila Healthcare, among others (Berndt, Ling, and Kyle 2000, Indian Pharmaceutical Guide 1996).

The second way in which competitive production in developing countries could erode profits in rich countries is if drugs sold cheaply in one country were exported into higher-priced markets. In most cases such movements are illegal because patents in the rich countries give owners the right to prevent imports. The U.S. and the European Union, for example, restrict the import of a patented product even when the first sale of that product abroad was by the patentholder, his licensee or subsidiary. ${ }^{31}$ The issue here, then, is the ability to enforce existing rights to prevent infringing imports. The extensive regulation of rich-country pharmaceutical markets makes hidden imports in bulk difficult, and again empirical evidence that this has been a significant problem is limited.

\section{Going Forward}

Now, the world may be changing in ways that will make it more difficult for pharmaceutical firms to separate their rich- and poor-country 
markets. The high-profile scrutiny of the cost of antiretroviral drugs has drawn public attention to cross-country price differences that encompass the developing world. This attention is the result of both the magnitude of the humanitarian crisis created by AIDS and related conflicts over TRIPS implementation. ${ }^{32}$ Multinationals have already indicated that they may withdraw from research on antiretrovirals because of the pricing constraints this attention puts them under. ${ }^{33}$ Public attention may diminish with time, particularly if pricing issues related to antiretrovirals are resolved, but it may well be a continuing feature of the political environment in which firms must operate.

Further, with the rapid growth of the Internet and online pharmacies, it will become increasingly difficult to control the physical movement of products. Once developing-country firms have developed sufficient reputations for quality, one can easily imagine hundreds of thousands of packets crossing borders by mail. Patentees will be hard pressed to identify such individual infringements and reluctant to sue their customers. Internet sales also pose a safety threat to consumers. In a statement to the U.S. Congress on May 25, 2000, a commissioner of the U.S. FDA stated that "Internet technology can obscure the source of the product. ... [The agency] believes that illegal online drug sales pose a significant public health risk. . . . The sale of drugs to U.S. residents via foreign websites is an extremely challenging area." (Hubbard 2000.)

\section{Policy Response}

Is the extension of pharmaceutical patent protection to poor countries a good policy response to potential price erosion in rich-country markets? Global patent rights will only help innovative firms deal with consumers' sensitivity to differences in prices if they use the control that patents give them to price fairly uniformly across countries. If firms set uniform prices, these prices will reflect demand conditions in the major, rich-country markets. As a solution to the problem of crosscountry price comparisons, this approach would clearly be extremely damaging to the poor. A more appropriate alternative, though difficult, would be to educate consumers in the rich countries about the reasons for price differences and to develop domestic policies aimed at making pharmaceutical prices a less politically sensitive issue.

Global protection of their patented products would give owners better control over their physical movement. Firms would be able to monitor total sales in poor countries and thus detect likely sources of 
infringing exports to other markets. Allowing them this control could beneficially lower the overall resources devoted to enforcement and make patents in the developed world more effective. If the concern were the physical movement of products rather than consumer price sensitivity, patentees could adhere to marginal-cost pricing in the developing world. However, this is not where their incentives naturally lie, and as a result such a system would require constant monitoring. Oxfam, one of the major NGO campaigners for lower drug prices, says: "Although an equitable pricing system [by firms with the WHO] makes drugs cheaper in poor countries, it should be seen as a complement to the policy of maintaining a low level of patent protection in poor countries and letting generic competition reduce prices. Equitable pricing does pose a significant administrative challenge, which simply does not arise with the market-based approach." (Oxfam 2001a; italics mine.) Again there are alternative policies for addressing the problem. For example, developing countries can improve export controls, require manufacturers to record supplies so that total sales can be monitored, and require drugs to be colored and packaged so as to make their location of origin more apparent. Note that all of these, including the last, require the cooperation of poor-country governments to resolve a problem that is primarily of concern to rich-country consumers and firms. This could be part of a general agreement on a revised patent framework that would benefit firms and consumers in both rich and poor countries.

\section{Avenues to Differentiated Patent Protection}

The previous sections have suggested that the optimal global framework for pharmaceutical patents might require differentiating the effective protection given to products in accordance with their extremely different global markets. Patents in poor countries will be a more valuable stimulus to innovation in therapeutic areas where their consumers are the major market. Several standard intellectual property and regulatory mechanisms could be considered for this purpose. First, poor countries could directly legislate that pharmaceutical innovations related to a list of global diseases are not patentable. Second, most countries, rich and poor, regulate pharmaceutical prices, and this is not restricted by treaty. Thus countries could grant patent rights on all drug products but use price control regulations to differentiate the value of those patent rights. Third, and more controversially, the TRIPs agreement allows countries to issue compulsory licenses to attain pub- 
lic health goals. Compulsory licenses are nonexclusive licenses to use a protected innovation in return for reasonable royalty payments to the patentee. As with price control, higher "reasonable royalties" could be paid on drug product innovations of particular interest in developing countries. We assess each of these options in turn.

\section{Selective Patentability}

There is precedent for simply stating that pharmaceutical innovations related to certain diseases are not patentable. Previous to the TRIPS Agreement, Cartagena Agreement members-Bolivia, Colombia, Peru, and Venezuela-excluded products on the WHO essential drugs list from patentability. This approach is appealingly straightforward.

Note that, at the time of application, the information needed to differentiate across innovations by disease is not available in any practical sense. The therapeutic uses of an innovation would be difficult to glean from its patent specification. Often the uses of a pharmaceutical product are only discovered after considerable time has passed. Because of the difficulty in making a determination at grant, in practice all pharmaceutical products would be treated as though they were patentable, and the issue of invalidity on the grounds of a particular pharmaceutical use would be addressed in subsequent litigation, if at all. This has the advantage that in many cases no resources would be expended on classifying different patents or patented products.

Although it appears the most straightforward way to differentiate protection, selective patentability does have some major drawbacks. Most importantly, at this time such a restriction would be incompatible with the existing treaty agreement. Article 27.1 of TRIPS states "... patents shall be available and patent rights enjoyable without discrimination as to the place of invention, the field of technology and whether products are imported or locally produced." Although several explicit exemptions are listed, any policy that directly differentiates legal treatment across diseases is in certain conflict with TRIPs and would require treaty renegotiation. As agreements, even partial ones, in this area have been reached only after intense negotiations and with great difficulty, this is a serious issue.

It would be necessary to determine a clear and reliable way to identify nonpatentable products should litigation arise. If there were any ambiguity, considerable resources could be devoted by both sides in an effort to influence the decision in each case. Further, firms considering 
competitive entry could be deterred altogether by the prospect of high legal costs, even when the patents protecting a product are invalid.

Finally, any policy that gives differential patent treatment to therapies for some diseases will affect patient groups differently. As a result, domestic political pressure would almost surely make differentiation along the lines required (that is, exempting from protection only global disease products) untenable. Any differentiation would more likely reflect the relative strength of domestic patient lobby groups or the particular pressures brought to bear by firms. One could isolate the policy from continuing political pressures by making it difficult to change the type of product innovations deemed nonpatentable, perhaps stating them specifically in the patent law. But to the extent that this is successful, the policy becomes inflexible in the face of changes in product markets.

\section{Price Control Regulation}

Rather than approaching differentiation through the intellectual property system, a price control regime could be designed to have a similar effect. Products treating global diseases could be put under very strict control, and those treating diseases found primarily in poor countries could be allowed higher price-cost margins.

There are two major advantages associated with this approach. First, it does not require any modification of TRIPs. The strengthening of worldwide intellectual property protection could continue for all pharmaceutical products as required by treaty. Second, price control regulation is already a feature of the pharmaceutical markets in both rich and poor countries. Hence, although firms may not be happy about it, the principle of regulating prices is not likely to be challenged in the international arena.

However, there is an important drawback to relying on regulation to keep down prices when patent rights are strong. Patentees would retain control over sales in the developing-country market and could, if controlled prices were viewed as too low, simply keep patented products off the market altogether. This is not hypothetical. Recently the head of Pfizer announced that it would threaten to withhold new treatments from France unless the government would allow higher drug prices. Further, he claimed that many other countries could see access withdrawn, and the CEO of AstraZeneca is quoted as saying "I think all the major pharmaceutical companies are making decisions not 
to launch products" (Financial Times, December 10, 2001). Thus price control can only ensure low priced access if the government is able to license others to work the patent in response to a refusal by the patentee to supply the market. Under current rules, a refusal to supply might be sufficient to trigger the national emergency provisions allowing compulsory licensing. However, even if so, one would first see drawnout negotiations over price and then over reasonable royalties and other suppliers would need to be found quickly for licensing to be effective. This process could cause considerable delay, particularly in those countries with weak regulatory capability-that is, the poorest.

Regulating through price controls rather than competition has the further drawback that it demands continuous monitoring to ensure that any price ceilings imposed are not evaded by manufacturers or retailers. This is also particularly difficult in countries with limited regulatory capability. Articles have been written in India, for example, pointing to evasion of price controls in that country (Rane 1995).

Finally, this approach shares with the previous one the information and political problems associated with differentiating protection. In this case the price control board would have to identify the diseases each product could treat and determine if they were on a global disease list. It would be simpler than the problem faced by a patent examiner since this determination would only need to be made at the time of marketing, when information from the marketing approvals process might be available to inform the decision. However, the political difficulties would be more acute when using price regulation. Because of the clear link between the ongoing decisions made by regulators and the prices faced by consumers, a price control board would be a obvious target for dissatisfied patient groups.

\section{Compulsory Licensing}

The TRIPS agreement puts various conditions on the use of compulsory licenses. These conditions were purposefully left vague in the treaty because of lack of agreement. They continue to be contentious. Their clarification was an item that the WTO Ministerial Conference returned to in its "Declaration on the TRIPs Agreement and Public Health" made in November 2001. The procedural conditions required for licensing stated in TRIPs include: treating each license request on its individual merits; considering a compulsory license only after negotiations with the patentee have failed; and allowing decisions to be 
subjected to independent review. However, situations of national emergency allow the override of these procedural conditions so as to allow countries rapid access to treatments. Remaining points of disagreement related to use of compulsory licensing are outlined in detail in Abbott (2002b).

Compulsory licensing in order to allow competition to lower prices avoids delays due to protracted negotiations between the government and patentees over the level of controlled prices. Because of the procedural conditions, however, reliance on a compulsory license system could also entail substantial delay in new drugs' arrival on the market. Firms considering competitive entry will not begin to make the required investments until they know that they will be able to proceed with production and sales. For this reason, Scherer and Watal (2001), in a discussion of compulsory licensing experience, commend the approach that was taken by the Canadians, who set $4 \%$ as the reasonable royalty payment for all such licenses. By doing this, the licensing board avoided having to investigate $R \& D$ costs and market conditions before setting each fee. The average licensing approval time of only 10 months was possible precisely because no attempt was made to differentiate across products.

The TRIPS agreement also creates two problems for differentiating through licensing. As with selective patentability, a compulsory licensing scheme that differentiated treatment across pharmaceutical innovations on the basis of diseases treated would run counter to Article 27.1 of TRIPs. Further, patentees given lower royalty rates on this basis could well argue that this was not "reasonable." ${ }^{134}$ Again, a treaty amendment would be needed to allow this form of discrimination. Second, as the TRIPs agreement now stands, firms are limited in their ability to produce for export under a compulsory license. Since this means that there would be no source of imports, compulsory licensing would only be effective in countries with manufacturing capacity. This issue was raised at the WTO Ministerial Conference. It was not resolved there, although the TRIPS Council was instructed to furnish a proposal regarding export under compulsory license by the end of 2002.

As with price control, under a differentiated compulsory licensing scheme the correct allocation of every patented product would have to be determined, with firms' having every incentive to make this as hard as possible. In order to differentiate effectively, one would need to define categories of products to receive different royalty treatment, 
and then have a quick method for identifying the category into which a particular product should fall. This would be both difficult and costly.

Beyond the informational problem, the more difficult aspect of licensing products for different types of diseases differently again might be political. Having seen a compulsory license granted for a global disease product with a "reasonable royalty" of $1 \%$, those suffering from malaria might well object to a "reasonable royalty" of $30 \%$ or $50 \%$ being required of producers of their drugs, regardless of the justification.

\section{A New Mechanism for Differentiating Protection}

We have seen that each of the standard intellectual property and regulatory policies that might be used to differentiate protection has very significant drawbacks. This section describes a new mechanism that would make differential protection a more feasible policy option. The mechanism effectively requires patent owners to choose either protection in the rich countries or protection in the poor countries (but not both), whenever they have a pharmaceutical innovation related to a listed global disease. Given this choice, such patentees would chose to maintain protection in rich-country markets and allow competition in the poor countries. Owners of patents related to nonglobal diseases, on the other hand, would be allowed protection worldwide. This section briefly describes the policy from the perspective of U.S. law, followed by a discussion of coordinated implementation across countries. Legal details, including a discussion of TRIPS compatibility, are in Lanjouw (2002b).

\section{The Mechanism}

For simplicity first assume that there are: two countries, the U.S. and India; two diseases, cancer representing global diseases and malaria representing all others; and three companies, PharmaUS, CiplaIndia, USGeneric, each representing a type of firm. The basis of the mechanism is the obligation in U.S. law that the inventor must apply first for a U.S. patent when an innovation is made in the U.S. To make subsequent applications abroad the inventor requires a foreign filing license from the U.S. PTO. Specifically, U.S. law provides that "[e]xcept when authorized by a license obtained from the Commissioner of Patents a person shall not file or cause or authorize to be filed in any foreign country prior to six months after filing in the United States an application for 
patent or for the registration of a utility model, industrial design, or model in respect of an invention made in this country." (35 U.S.C. \$184). This domestic filing requirement is in place for the purpose of national security. Failure to obtain the license before a foreign filing renders the U.S. patent invalid.

The policy is to stipulate that, when a patentee petitions for this license, he does so in something like the following form:

I, the undersigned, request a license to make foreign patent filings covering the invention described in U.S. patent application no. $X$, with the understanding that this permission will not be used to restrict the sale or manufacture of drugs for cancer in India by suing for patent infringement in India.

\section{Basic Outline of Why It Works}

Suppose that PharmaUS has a cancer product protected by a single patent in the U.S. and in India. The company obtains marketing approval in both countries and sells the product. Now CiplaIndia (or USGeneric) enters the Indian market with its own version of the same product. PharmaUS can choose one of three strategies:

- Continue to sell the product. Making this choice, the firm would need to lower its price to remain competitive with new entrants. PharmaUS would then obtain no benefit from its Indian patent.

- Exit. PharmaUS might be uncomfortable selling at prices low enough to be competitive in India and thus might choose to withdraw from the Indian market. With this choice, PharmaUS would continue to exercise its rights in the U.S. market, while the Indian market would be served by other manufacturers.

- Sue for infringement. The company has a valid patent in India. Nothing prevents the company from choosing to protect its rights in India, on the basis of its patent there, in an Indian court. If it does so, however, either CiplaIndia or, more likely, USGeneric, can claim in a U.S. court that, by attempting to stop sales of the cancer product in India, PharmaUS has rendered its U.S. patent unenforceable. This is so because, by taking this action, PharmaUS has falsified the declaration it made to the U.S. PTO to obtain the foreign filing license. Patentees have a general duty to deal with the patent office in good faith, and failure in this regard is grounds for rendering a patent unenforceable.

Suppose now that the innovation had been for a malaria product. Again PharmaUS could choose either to compete or to exit the market 
with the entry of CiplaIndia. Again its third option is to sue for infringement. Now, however, the suit would give no grounds for rendering the U.S. patent unenforceable. The declaration made by PharmaUS to obtain its foreign filing license says nothing about malaria.

Thus, in the case of a patent for a cancer product, PharmaUS's two choices are effectively between protecting its profits in the U.S. and protecting them in India-but not both - as desired. The key point is that the firm will not sue in India for infringements of cancer product patents, because it will not want to jeopardize its U.S. patents. Knowing this, CiplaIndia will enter the market, and prices in India will fall. With a malaria product, PharmaUS will prosecute infringements in India and therefore has effective protection in both the U.S. and India. Thus incentives for investment in malaria products are maintained.

\section{What Is a Cancer Product?}

A clear procedure is needed to determine when an Indian product corresponds to a particular disease. One possibility is the following. All products marketed in the U.S. are approved for specific indications. To render unenforceable PharmaUS's patent, CiplaIndia or USGeneric could be required to take the Indian product and apply to the U.S. FDA for an abbreviated new-drug approval. The applicant would claim the Indian product's equivalence to one already marketed in the U.S. with a cancer indication. The procedure would be precisely the same as that already followed for any generic on the expiry of a patented product. The case that the Indian product is for cancer would be made with the issuance of a U.S. FDA report confirming bioequivalence.

\section{Procedure to Determine Content of Declaration}

Above we assumed that there is a single poor country, India, and a single disease with a predominantly rich-country market, cancer. The declaration would, in fact, specify lists of countries and lists of diseases. A straightforward, transparent, and objective procedure is needed to determine these lists. The patent office would update the license declaration periodically-say every two years-following the stated procedure, and would not need to make any judgments of its own about the content of the declaration.

Before discussing how to specify these sets, it is important to emphasize why we would not want to simply pick the poorest countries 
and then apply the policy to all diseases. If we were to do so, the design of the mechanism would ensure that firms' own choices would automatically keep incentives roughly in order. For products where potential profits were greater in the U.S., patentholders would refrain from enforcing Indian patents. For products more valuable in India they would choose to prosecute infringements there and give up the U.S. market. Thus, responding on the basis of their knowledge of global market opportunities, firms' behavior would reflect the relative demand for new products, as one would want. The problem is that, when a product has a market that is fairly evenly spread across the two countries, allowing the innovating firm protection in one just country or the other would have a substantial effect on its profits. Thus, to maintain research incentives the declaration should be limited to diseases with markets that are concentrated in the rich countries. A procedure is needed to determine which diseases these are.

Starting with a group of poor countries, the goal is to identify those diseases where the potential profit coming from sales in that group of countries is less than, say, $2 \%$ of global profits. A practical approach would be to set up a procedure with two steps, the first identifying increasingly broad groups of poor countries, and the second, appropriate diseases for each group. An example would be the following:

- Step 1. Ask countries with GDP less than $\$ 5000$ per capita whether they object to being included in the declaration. ${ }^{35}$ Place remaining countries with GDP per capita less than $\$ 500$ in group A, those with GDP per capita less than $\$ 2000$ in group B, and those with GDP per capita less than $\$ 5000$ in group $C$. The GDP figures to be used are the United Nations annual statistics. (Note that the poorest countries, in group A, are also in B and C, and so on.)

- Step 2. Using data on pharmaceutical sales by disease class, calculate, for each class, total world sales and then sales in each of the country groups A, B, and C. Include on disease list A all classes where the sales for country group $A$ are less than $2 \%$ of world sales, and similarly for disease lists B and C. (See Lanjouw 2002a for a discussion of data and the use of sales information as a proxy for profits.)

For the poorest of poor countries, of group A, probably all disease classes would qualify and, effectively, no protection would be afforded pharmaceuticals in those countries. Moving to $B$, the group gets larger and also somewhat richer. Some disease classes may no longer qualify, 
and patent protection would be available on those. For the largest group C, yet fewer diseases would qualify, and the scope of protection would widen further. Once a country attained a GDP per capita greater than $\$ 5000$, protection would be available for all products.

This example is meant only to illustrate how the procedure could be structured-other GDP cutoffs and more country groups could be chosen. Similarly, a number other than $2 \%$ might be appropriate. Increasing its value would allow the policy to encompass a larger number of diseases and confer greater price benefits on the poor, but would begin to more significantly dampen research incentives. Structured in this way, the procedure combines certainty with flexibility. The effective patent rights available to a firm with respect to a particular innovation are determined by the content of the declaration when it is signed at the time of patent application. These remain the same throughout the life of the patent, and the firm can make its marketing decisions accordingly. At the same time, the content of the declaration evolves to reflect changes in pharmaceutical markets and the development of countries. A country starting out in group B, for instance, would move to group $C$ as it grew richer and eventually would not be included in the declaration at all.

\section{International Coverage}

The U.S. government could implement this policy on its own. Then, however, inventions made by scientists working outside the U.S. would not fall within its ambit. This would limit the policy's effectiveness and is unlikely to be politically tenable. Thus, there would probably need to be coordination among countries having innovative pharmaceutical industries.

Pharmaceutical firms tend to concentrate their research in a limited number of centers located in developed countries. Table 4.2 gives the nationality breakdown of inventors of U.S. pharmaceutical patents. (This should be representative of all patenting, since innovations of any importance would be patented the U.S.) It shows that R\&D output is highly concentrated in the U.S. and a few other countries. Thus by far the preponderance of activity could be covered with coordination among a limited number of governments. Implementation by eight countries alone would cover over $90 \%$ of all pharmaceutical patents. Of course, firms could respond by moving their research centers to nonimplementing countries. However, firms choose their research 
Table 4.2

Percentage of U.S. pharmaceutical patents and their inventors of different nationalities

\begin{tabular}{llllll}
\hline & \multicolumn{2}{l}{ Patents (\%) } & & \multicolumn{2}{l}{ Listed inventors (\%) } \\
\cline { 2 - 3 } Nationality & National & Cumulative & & National & Cumulative \\
\hline U.S. & 50.68 & 50.68 & & 42.75 & 42.75 \\
Japan & 11.36 & 62.04 & & 17.54 & 60.29 \\
Germany & 9.21 & 71.25 & & 12.49 & 72.78 \\
U.K. & 6.94 & 78.19 & & 5.86 & 78.64 \\
France & 5.86 & 84.05 & & 6.03 & 84.67 \\
Switzerland & 2.79 & 86.84 & & 1.99 & 86.66 \\
Italy & 2.56 & 89.40 & & 2.69 & 89.35 \\
Canada & 2.00 & 91.40 & & 1.67 & 91.02 \\
\hline
\end{tabular}

Note: The nationality of a patent (the first set of columns) is the country of residence of the first-listed inventor.

Source: Calculations by Jeffrey Furman, from U.S. PTO Technology and Assessment Forecasting division data, 2001. It includes all U.S. pharmaceutical patents applied for during the period 1985-1995.

locations for a variety of reasons, and discovery research, unlike manufacturing, tends to be done at a few centers. As the gains from avoiding the policy are small, it seems highly unlikely that they would take such action. ${ }^{36}$

Lanjouw (2002b) describes features of the intellectual property law in the U.K., France, Germany, Canada, and Japan that are relevant to the implementation of this policy. There are two important elements common to the law in each of these countries. First, each of the countries has some form of national-security-related provision regarding the treatment of patent applications. Thus their laws acknowledge that national interests may limit the actions of patentees - in particular their ability to disclose information. Second, in none of the countries is there a general duty to deal in good faith with the patent office. However, in each of them patents may be invalidated on the grounds of insufficient disclosure-that is, when the invention is not described sufficiently clearly and completely for someone skilled in the art to reproduce it. Thus the basic principle that patent rights are a privilege granted by society and may be retracted if a patentee does not fulfill requirements designed to further social goals is there. At this time the U.K. has a foreign-filing license obligation and procedures quite close to those in the U.S.; Germany and France have more limited obligations but with similar features; Japan and Canada currently place no restrictions on foreign patent filings. 


\section{Advantages}

The mechanism described may appear complicated, but its structure confers some important advantages:

TRIPS Compatiblity Requiring a declaration for a foreign filing license is not de jure discriminatory, because it is required of all patentees wishing to file abroad. If you have an innovation for a drug, you would be required to sign the declaration; if you have an innovation for a toaster oven, you would be required to sign the declaration. It is, of course, de facto discriminatory, since that is the intention. However, de facto discrimination has not been ruled incompatible with the TRIPS agreement (see Lanjouw 2002b for further discussion). As a result, no amendment to TRIPs would be required using this approach.

Information A major advantage of this policy is that it does not require information that is expensive to obtain. The mechanism is triggered by a lawsuit. An important reason for this feature is that when an infringement suit is filed to prevent the sale of a product, it is on the basis of a set of patents. In order to be successful in prosecuting its suit, the patent-owning firm has a strong incentive to correctly identify the patents it believes best protect the product in question. This resolves the otherwise intractable problem of how to identify the therapeutic use of innovations described in patent specifications. As noted above, in practice selective patentability would operate in the same manner, with invalidity only assessed as part of a suit. The important difference is that here the patentee has a strong incentive refrain from suing when he has no grounds, because so much is at stake (his U.S. patents). With selective patentability the patentee has nothing to lose from filing and prosecuting a case beyond court costs in the developing country. Therefore, with selective patentability one would expect suits and threats of suits to be far more common.

Unlike the other alternatives, the policy makes use of firms' better information about the relative size of markets in different countries. If one were to simply state that innovations related to cancer were not patentable, the restriction would apply to all cancer products. With the policy described above, patentees would have the ability to choose the better market, rich or poor. This would be an advantage in maintaining incentives for research on developing country-specific diseases within a class. Suppose, for example, that there were a rare form of cancer 
only found in Africa. For products treating this form of cancer, patentees would choose to protect their patents in Africa and any profits available would be preserved.

Administration Under a selective compulsory licensing or pricing scheme the correct allocation of every patent or patented product would have to be determined. Price control would require continuous monitoring. The proposal outlined here-where firms would rarely trigger an event making it necessary to classify a product-is self-enforcing and only uses information easily available. As a result it would require almost no expenditure on administration or enforcement.

Targeting Clear procedures determine the country and disease groups to go on the declaration, and the legislation to establish the procedures is required only in the developed countries and only at the time of implementation. This insulates the policy from lobbying by firms and by patient groups in the developing world. With the alternatives, developing-country governments would be subject to pressures having little to do with the underlying rationale for differentiated treatment.

\section{Conclusion}

We have seen that pharmaceutical product patents promise benefits and costs that differ with the characteristics of diseases. Building up a stronger portfolio of products to prevent and treat diseases that primarily affect poor countries will require a package of policies. Encouraging investment by the private sector with globally available and welldefined patent rights, together with greater financing through push and pull mechanisms, could end the acute shortage of pharmaceutical products for the developing world. For major global diseases, however, the justification for extending patents in poorer countries is less clear. Protection in rich-country markets provides enormous incentives to invest in research on such diseases, incentives that dwarf any possible contribution that would come from the developing world. ${ }^{37}$ These products diffuse rapidly to poor countries even absent protection there. Granting innovative firms global control over distribution in poor countries does have some advantages in helping firms to protect against price erosion in their major markets. However, these benefits come at a high cost, and there are alternative ways to address the chal- 
lenges of separating rich- and poor-country markets for global-disease products. If feasible, then, the optimal framework of global patent rights for pharmaceuticals would treat innovations differently in accordance with their world markets. The benefits of patent protection could be varied across types of drugs by defining some as nonpatentable subject matter, by selectively issuing compulsory licenses, or by controlling certain prices more tightly. However, all of these standard approaches have serious political, information, and enforcement problems that would prevent them from being implemented effectively. The new mechanism presented here, operating through a foreign-filing license obligation, is structured to avoid these problems. It would allow the implementation of a global patent regime that was sensitive to the development level of countries and the characteristics of particular drug markets.

\section{Notes}

I thank Peter Lanjouw and the editors for comments on this paper. Many people have also contributed to the development of the new policy mechanism described in section VI, and I greatly appreciate their time and attention. Special thanks are due to the members of the Canadian, Japanese, U.K., French, and German patent offices who have helped me to understand the details of their patent systems, and to Martin Adelman and Richard Wilder for their patience in answering questions about U.S. law. Useful comments have been received from representatives of Oxfam, the pharmaceutical industry, the U.S. Patent and Trademark Office, and from seminar participants at meetings sponsored by the Berkeley Center for Law \& Technology, the Centre for Innovation Law and Policy of the University of Toronto, New York University Law School, the NBER, CSIS, the U.S. Treasury Department, the UNDP, the World Bank, and the WHO Commission on Macroeconomics and Health. Jeffrey Furman, Boston University, and IMS HEALTH Global Services were generous in providing statistics.

1. For example, in 1984, the U.S. Congress passed a revision of the Trade and Tariff Act, which authorized the U.S. government to take retaliatory action against countries failing to give adequate protection to intellectual property (Section 301). The Act was strengthened in 1988 with legislation mandating that each year the U.S. Trade Representative identify countries without adequate protection.

2. The date by which this must happen varies across countries. The least-developed countries recently obtained an extension to 2016 of the transition period for the adoption or enforcement of pharmaceutical product patents.

3. At the November 2001 World Trade Organization Ministerial Conference, a coalition of sixty nations, called the Africa Group, pressed for new rules affirming the freedom to make use of patented innovations to protect public health and for more lenient compulsory licensing provisions to allow exports to countries without domestic manufacturing capacity. See also Oxfam (2001a, 2001b), referring to its Cut the Cost campaign, and issues of Access Nerws published by Médecins Sans Frontières as part of its "Campaign for Access to Essential Medicines. 
4. The difficulties of establishing a well-functioning patent system are not well appreciated. At the time it committed to TRIPS, for example, there were only 151 registered patent agents in all India (Controller General of Patents, Designs and Trade Marks, 1996). The business community, courts, and police all need to develop experience. A Delhi patent attorney tells the story of an early copyright infringement case where the police stapled confiscated CDs into a notebook, thereby destroying the evidence (interview with Pravin Anand, 1997).

5. It has been suggested that innovating firms need control of sales in poor countries to restrict the misuse and overuse of pharmaceuticals there. In this view, limiting rather than expanding access is the objective, in which case there clearly is no trade-off associated with patent protection. While recognizing the importance of the problem, this paper will start from the premise that increasing access is desirable, and that pharmaceutical misuse should be addressed by governments rather than by relying on firms to curtail usage.

6. In a careful statistical study of pharmaceutical research programs, Henderson and Cockburn (1996) find sharply decreasing returns to greater investment in individual projects. They do find advantages to size-but they come only at the level of the overall research program.

7. The use of pharmaceuticals is only one way to combat disease. There are many others, such as the provision of clean water, primary health care, education, and bednets. This paper will treat only the role of intellectual property in improving pharmaceutical availability and not the broader issue of the relative importance of pharmaceuticals in providing better health.

8. The experience with "orphan" drugs illustrates. The U.S. Orphan Drug Act gives tax benefits and exclusive marketing privileges to applicants for new-drug approvals related to products that would otherwise be uneconomic to discover and bring to market. It identifies qualifying products as those with expected patient populations of less than 200,000 . It has been suggested that industry has incorrectly obtained orphan drug designations on more prevalent forms of cancer, AIDS, and asthma. See testimony before the U.S. Senate by James Love at /http://www.cptech.org/ip/health/orphan/orphan92.html $\rangle$. In light of these "blockbuster orphans," Congressman Waxman, sponsor of the original legislation, sought amendments to limit benefits for profitable orphans. See 〈http: / / www.house.gov/waxman/pharm/orphan/orphan.html〉.

9. Patents grant monopoly rights over a specific innovation-not, for example, over a therapy area. There may be intense competition between a patented product and alternative drugs or other medical treatments for a given disease (as well as competition with other nonhealth goods that a consumer might want to purchase). What is limited is direct imitation of the patented product.

10. More fundamentally, term limits demonstrate the basis of our patent laws in social welfare rather than natural rights, since the latter should not expire.

11. Lerner (2002) provides a detailed account of the many other limitations placed on patent rights by OECD countries over the past centuries.

12. The World Health Organization estimates that there are 28 countries where over half of all health expenditures are covered out of pocket by individual consumers (WHO 2001).

13. For formal models of some of the trade-offs associated with the extension of patents to additional countries see Deardorff (1992), Chin and Grossman (1990), and Diwan and Rodrik (1991). 
14. DALYs are estimates of years of life lost or lived with a disability, adjusted for its severity. Global burden estimates are for 1990 WHO (1996); mortality and DALY figures are found in WHO (1999). For the disease list see Lanjouw and Cockburn (2001).

15. It is often suggested, incorrectly, that pharmaceutical firms located in developing countries concentrate on diseases specific to their domestic markets. In fact they face incentives similar to firms elsewhere. A survey of Indian firms in 1998 found that only $16 \%$ of their R\&D was directed towards LDC markets (Lanjouw and Cockburn 2001).

16. The total includes all public health R\&D (not necessarily drugs) in developing countries, plus public expenditure in developed countries on tropical or relevant vaccines, plus any R\&D expenditure, public or private, in developed countries involving collaboration with an institution or scientist located in a developing country.

17. The data come from INPADOC and include information on patent applications and grants from all the major patent offices in the world. Patents filed in different jurisdictions that cover the same invention are organized into "families," which here can be thought of as collections of all worldwide patents claiming a particular molecule. Counts of these families thus capture patenting activity in all major patent-granting countries.

18. The share of real spending by the National Institutes of Health directed towards tropical diseases, never more than 1\% actually fell between 1996 and 1999 (Lanjouw and Cockburn 2001).

19. PhRMA, 2001, "Backgrounders and Facts" at /http://www.phrma.org/publications).

20. Although poor countries tend to allocate a smaller share of their GDP to health, income disparities drive these differences. If the 17 countries had devoted the same share of GDP to health as the U.S. $(12.9 \%)$, only one of them would have reached even $\$ 50$ per capita in spending (compared to over $\$ 4000$ for the U.S.). Some poor countries have directed a relatively sizable share of their resources to health, but even then to little effect. Consider: Luxembourg spent $6.0 \%$ of its GDP on health, for a per capita expenditure of $\$ 2574$. Malawi spent $7.2 \%$, to manage a per capita expenditure of $\$ 12$.

21. Stringent price control in a country could produce the same effect as low purchasing power. Patent protection would not raise prices, nor would it stimulate innovation. Of course, the policy response may be different. In the case of low incomes outside funding is important, while in the case of price control domestic consumers may have the ability to pay higher prices themselves.

22. See Eisenberg (1996) for a detailed discussion of the history of the debate.

23. Authorized by the Federal Technology Transfer Act of 1986.

24. Other issues would enter an assessment of the benefits of these pieces of legislation. A particular concern of observers, for example, is that allowing universities to license their output may have a damaging effect on the open nature of university research and on the choice of research programs.

25. The related drawback is that they may wastefully replicate each other's research efforts.

26. Studies in Brazil, Mexico and the Dominican Republic also suggest that, as in the developed world, obesity is more prevalent among the poorer members of society once modest levels of income are attained. 
27. U.S. FDA, Center for Drug Evaluation and Research, "NMEs Approved in Calender Year _" at 〈http://www.fda.gov $\rangle$.

28. The report was done in 1990, and a few of the NCEs developed towards the end of the 1975-1989 period may have ended up being globally launched after 1990 .

29. This was the Medicine Equity and Drug Safety Act of 2000, also known as the Jeffords Amendment. Oddly, the Act only concerned itself with restrictions on imports due to FDA approval rules and ignored those derived from intellectual property. Thus, even if it had come into force, patentees would have been able to block reimportation of their products on the basis of their patent rights (Barton 2001). For press coverage see The New York Times, September 27, 2000.

30. Although never implemented, President Clinton's 1993 Health Security Act proposed using the lowest price in 22 other countries as a benchmark for determining the reasonableness of prices set for newly introduced drugs.

31. That is, they restrict "parallel imports." This is not required by TRIPs, and is not the case, for example, between the member states of the European Union.

32. For example, the South African government passed a law in 1997 to permit parallel imports of HIV drugs (from lower-priced countries). It came under intense pressure from the U.S. government to repeal the law and was subjected to a lawsuit brought by a consortium of pharmaceutical firms. See Abbott (2002a) for details. The article "Crimes Against Humanity" in Time Magazine, February 2001, is an example of popular press coverage of the suffering due to HIV/AIDS.

33. Harvey Bale, Director General of the International Federation of Pharmaceutical Manufacturers Associations (IFPMA), pointed out last year that the number of anti-AIDS compounds under development had fallen for three years as a campaign against the big companies had unfolded (Reuters, September 19, 2001). The IFPMA quotes two industry leaders as saying that "if enthusiasm for compulsory licenses becomes great, there will be soon no more patents on AIDS drugs to compulsorily license-because new product development in this critical field will decline dramatically." (At 〈http:/ / www. ifpma.org .

34. The remuneration, according to Article 31(h), in the event a compulsory license is granted, must "take into account the economic value of the authorization."

35. Domestic pharmaceutical firms in poor countries may wish to engage in cooperative ventures with multinational companies. If the latter make the availability of domestic patent rights a prerequisite to such interaction, and if a poor-country government views its industry's concerns as more pressing than its consumers' interests, it might prefer not to be on the list. Inclusion in the declaration should not be forced upon any country.

36. It might be relatively easy to shift activities from the U.S. to Canada-so it would be important that Canada be an implementing country.

37. Glaxo-Wellcome earned an estimated profit of around 7 million dollars per day from sales of Zantac just before patent expiry (The Economist, April 26, 1997).

\section{References}

Abbott, Frederick M. 2002a. "The TRIPS-Legality of Measures Taken to Address Public Health Crises: Responding to USTR-State-Industry Positions that Undermine the WTO." 
In Daniel Kennedy and James Southwick, eds., The Political Economy of International Trade Law: Essays in Honor of Robert Hudec. Cambridge: Cambridge University Press.

Abbott, Frederick M. 2002b. "Compulsory Licensing for Public Health Needs: The TRIPS Agenda at the WTO after the Doha Declaration on Public Health." Occasional Paper no. 9. Geneva: Quaker United Nations Office. At 〈http://www.quno.org〉.

Amo, Peter S., and Michael H. Davis. 2001. "Why Don't We Enforce Existing Drug Price Controls? The Unrecognized and Unenforced Reasonable Pricing Requirements Imposed upon Patents Deriving in Whole or in Part from Federally Funded Research." Tulane Law Review 75: 631-693.

Attaran, Amir. 2001. "Do Patents for Antiretroviral Drugs Constrain Access to AIDS Treatment in Africa." Journal of the American Medical Association. VO. 286, no. 15, pp. 1886-1892.

Barral, P. Etienne. 1990. "Research, Medicines, Competition, Communication: Fifteen Years of Pharmaceutical Research Results throughout the World (1975-1989)." Fondation Rhone-Poulenc Sante.

Barton, John H. 2001. "Differentiated Pricing of Patented Products." Commission on Macroeconomics and Health Working Paper Series no. 2. Geneva: World Health Organization.

Berndt, Ernst R., Davina Ling, and Margaret K. Kyle. 2000. "The Long Shadow of Patent Expiration: Do Rx to OTC Switches Provide an Afterlife?" Mimeo. Cambridge, MA: MIT.

Chin, Judith, and Gene Grossman. 1990. "Intellectual Property Rights and North-South Trade." In Ronald W. Jones and Anne O. Krueger, eds., The Political Economy of International Trade: Essays in Honor of Robert E. Baldwin. Cambridge, MA: Basil Blackwell: 90107.

Cohen, Wesley M., Richard R. Nelson, and John Strauss. 2000. "Protecting Their Intellectual Assets: Appropriability Conditions and Why U.S. Manufacturing Firms Patent (or Not)." NBER Working Paper no. 7552. Cambridge, MA: National Bureau of Economic Research.

Controller General of Patents, Designs and Trade Marks. 1996. "Patents: Twenty-second Annual Report, 1993-94." Nashik, India: Government of India Press.

Deardorff, Alan V. 1992. "Welfare Effects of Global Patent Protection." Economica 59: 3551.

Diwan, I., and Dani Rodrik. 1991. "Patents, Appropriate Technology, and North-South Trade." Joumal of International Economics 63: 79-90.

Eisenberg, Rebecca S. 1996. "Public Research and Private Development: Patents and Technology Transfer in Government-Sponsored Research." Virginia Law Review 82(8): 1663-1727.

Henderson, Rebecca, and Iain Cockburn. 1996. "Scale, Scope and Spillovers: Determinants of Research Productivity in the Pharmaceutical Industry." RAND Journal of Economics 1: 32-59.

Hubbard, William. 2000. "Statement before the Subcommittee on Oversight and Investigations." Committee of Commerce. U.S. House of Representatives. May 25. At 〈http:// www.fda.gov/ola/2000/internetsales.html>. 
Indian Pharmaceutical Guide. 1996. Volume 34. New Delhi: Pamposh Publications.

Institute of Medicine. 1997. America's Vital Interest in Global Health: Protecting our People, Enhancing our Economy, and Advancing our International Interest. Washington: National Academy Press.

Jaffe, Adam, and Josh Lerner. 2001. "Privatizing R\&D: Patent Policy and the Commercialization of National Laboratory Technologies." Rand Journal of Economics 32(1).

Kremer, Michael. 2001. "Creating Markets for New Vaccines-Part I: Rationale; Part II: Design Issues." In Adam B. Jaffe, Josh Lerner, and Scott Stern, eds., Innovation Policy and the Economy, volume 1. Cambridge, MA: The MT Press: 35-118.

Kremer, Michael. 2002. "Pharmaceuticals and the Developing World." Mimeo. Harvard University.

Lanjouw, Jean O. 1998. "The Introduction of Product Patents in India: 'Heartless Exploitation of the Poor and Suffering'" Growth Center Discussion Paper, Yale University, and NBER Working Paper no. 6366. January.

Lanjouw, Jean O. 2002a. "A Patent Proposal for Global Diseases." In Boris Pleskovic and Nicholas Stern, eds., The Annual World Bank Conference on Development Economics, 2001/ 2002. Washington: World Bank: 189-219.

Lanjouw, Jean. O. 2002b, forthcoming. "A Patent Proposal for Global Diseases: U.S. and International Legal Issues." Harvard Journal of Law \& Technology.

Lanjouw, Jean O., and Iain Cockburn. 2001. "New Pills for Poor People?: Empirical Evidence After GATT." World Development 29(2): 265-289.

Lerner, Josh. 2000. "150 Years of Patent Protection." American Economic Review Papers and Proceedings, 92 (May 2002) 221-225.

Médecins Sans Frontières. 2001. "Fatal Imbalance: The Crisis in Research and Development for Drugs for Neglected Diseases." Geneva: DND Working Group.

Mowery, David and Arvids Zeidonis. 2001. "Numbers, Quality and Entry: How Has the Bayh-Dole Act Affected U.S. University Patenting and Licensing?" In Adam B. Jaffe, Josh Lerner, and Scott Stern, eds., Innovation Policy and the Economy, volume 1. Cambridge, MA: The MIT Press: 187-220.

Nordhaus, William. 1969. Invention, Growth and Welfare. Cambridge, MA: MIT Press.

Oxfam. 2001a. "Fatal Side Effects: Medicine Patents under the Microscope." Oxford, U.K.: Oxfam.

Oxfam. 2001b. "Formula for Fairness: Patient Rights before Patent Rights." Oxfam Company Briefing Paper no. 2. Washington: Pfizer.

Pecoul, Bernard, Pierre Chirac, Patrice Trouiller, and Jacques Pinel. 1999. "Access to Essential Drugs in Poor Countries: A Lost Battle?" Journal of the American Medical Association 28(4): 361-367.

Rane, Wishwas. 1995. "Drug Prices: Sharp Rise after Decontrol." Economic and Political Weekly, November 25.

Santoro, Michael. 1995. "Pfizer: Global Protection of Intellectual Property." Case study No. 9-392-073. Harvard Business School. 
Scherer, F.M. 1972. "Nordhaus' Theory of Optimal Patent Life: A Geometric Re-interpretation." American Economic Review 62(3): 422-427.

Scherer, F.M., and Jayashree Watal. 2001. "Post-Trips Options for Access to Patented Medicines in Developing Countries," Commission on Macroeconomics and Health Working Paper no. WG4:1. Geneva: The World Health Organization.

UNAIDS/World Health Organization. 2001. AIDS Epidemic Update 2001. At 〈http:// www.unaids.org .

United Nations Development Programme. 2001. Human Development Report, 2001: Making New Technologies Work for Human Development. New York: Oxford University Press.

Watal, Jayashree. 2000. "Pharmaceutical Patents, Prices and Welfare Losses: A Simulation Study of Policy Options for India under the WTO TRIPS Agreement." The World Economy 23(5): 733-752.

World Bank. 1999. "Accelerating an AIDS Vaccine for Developing Countries: Issues and Options for the World Bank." Mimeo. At 〈www.iaen.org〉.

World Health Organization. 1996. Investing in Health Research and Development: Report of the Ad Hoc Committee on Health Research Relating to Future Intervention Options. Geneva.

World Health Organization. 1999. The World Health Report. Statistical Appendices. Geneva.

World Health Organization. 2001. The World Health Report. Statistical Appendices. Geneva. 
